\title{
PROJETO NIVELAMENTO EM MATEMÁTICA: UMA PROPOSTA DO GRUPO PETEE PARA REDUZIR A EVASÃO NA ENGENHARIA ELÉTRICA NO CEFET-MG CAMPUS NEPOMUCENO
}

Leonardo S. Ricardino - leonardoricardino119@gmail.com

Centro Federal de Educação Tecnológica de Minas Gerais, Departamento de Elétrica

Rua Vice Prefeito Walter Mansur, 604 - Bairro Santo Antônio

37250-000 - Nepomuceno - MG

Letícia S. Santos - leticiasotnas.1s@gmail.com

Rua José Augusto Moreira, 450, ap. 302 - Bairro Salgado Filho

37250-000 - Nepomuceno - MG

Breno M. Lima - massonbreno1991@gmail.com

Rua João Inácio Dias, 1122 - Centro

37250-000 - Nepomuceno - MG

Ignásia A.G.C. Ferreira - ignasiagcf@ gmail.com

Rua José Augusto Moreira, 450, ap. 101 - Bairro Salgado Filho

37250-000 - Nepomuceno - MG

Reginaldo B. Fernandes - reginaldo@ cefetmg.br

Rua Nicolau Bauth, 142 - Bairro Santa Filomena

37203-712 - Lavras - MG

Resumo: O programa de educação tutorial - PET do Centro Federal de Educação Tecnológica de Minas Gerais do Campus Nepomuceno, instituído em outubro de 2017, tem como base as três diretrizes: Ensino, Pesquisa e Extensão. Além dos outros projetos direcionados para Pesquisa e Extensão, este artigo trata de um projeto de Ensino denominado Nivelamento em Matemática. O Nivelamento em Matemática é uma disciplina que busca auxiliar os novos alunos com tópicos básicos do eixo da matemática, que é o suporte para as disciplinas do primeiro período. A princípio, este projeto foi realizado pelos próprios membros do grupo PET como uma aula, e posteriormente, a fim de promover maior interação entre calouros e seus veteranos, os petianos inovaram esse método para o Apadrinhamento, onde cada petiano ficou responsável por tirar dúvidas e trocar experiências com um ou dois calouros.

Palavras-chave: PET. Engenharia. Educação. Nivelamento. Matemática. 


\title{
1 INTRODUÇÃO
}

No Brasil, os cursos de graduação, principalmente os cursos de Engenharia, têm recebido cada vez mais alunos com inúmeras deficiências na sua formação escolar básica, o que se deve a fatores tais como: problemas socioeconômicos, formação inadequada dos professores e falta de material didático (ARAÚJO; LOPES; VILHENA, 2013). Desse modo, grande parte dos estudantes ingressos encontram dificuldades de acompanhar o curso superior devido à essa falta de conhecimento básico em ciências básicas (FORMIGA, 2011). Por consequência, isso acaba afetando negativamente o aluno, levando-o, muitas vezes, a evadir do curso.

Para SILVA FILHO et al. (2007), a evasão é, certamente, um dos problemas que afligem as instituições de ensino em geral. Verifica-se, em todo o mundo, que a taxa de evasão no primeiro ano de curso é duas a três vezes maior do que a dos anos seguintes. Ainda segundo o mesmo autor,

\begin{abstract}
a evasão estudantil no ensino superior é um problema internacional que afeta o resultado dos sistemas educacionais. As perdas de estudantes que iniciam, mas não terminam seus cursos, são desperdícios sociais, acadêmicos e econômicos. No setor público, são recursos públicos investidos sem o devido retorno. No setor privado, é uma importante perda de receitas. Em ambos os casos, a evasão é uma fonte de ociosidade de professores, funcionários, equipamentos e espaço físico.
\end{abstract}

Nesse sentido, é importante que as universidades busquem métodos alternativos para manter os discentes na instituição. Uma dessas alternativas é elaborar atividades de nivelamento. De acordo com BARRETO et al. (2011), as atividades de nivelamento têm um papel fundamental para resgatar a democratização do ensino, facilitando a permanência do aluno na universidade, resgatando a apropriação de conhecimentos esquecidos ou não apreendidos, facilitando a otimização do processo de ensino aprendizagem.

Diante dessa realidade, o grupo PET (Programa de Ensino Tutorial) Engenharia Elétrica do CEFET-MG Campus Nepomuceno desenvolveu, juntamente com a Diretoria do Campus, o projeto Nivelamento em Matemática. Esse projeto tem como principal objetivo proporcionar aos discentes ingressantes no curso de Engenharia Elétrica a oportunidade de minimizar a carência de conhecimentos em matemática básica, e promover essa integração do acadêmico com a instituição, visando um melhor desempenho dos acadêmicos nas componentes curriculares de graduação que compõem o núcleo básico da matemática, fazendo com que o processo de ensino e aprendizagem seja mais eficiente, e assim, reduzir a evasão dos estudantes nos primeiros períodos do curso.

\section{DESENVOLVIMENTO}

O Curso de Nivelamento em Matemática é uma disciplina extracurricular presencial com a duração de 30 horas/aula, destinado aos alunos ingressantes no curso de Engenharia Elétrica do CEFET MG Campus Nepomuceno, visando combater a evasão e reduzir o alto índice de 
reprovações, principalmente nas disciplinas de Cálculo, Geometria Analítica e Álgebra Vetorial, uma vez que tais disciplinas são essenciais à realização da graduação.

Por meio de aulas semanais durante o primeiro semestre de 2018, os integrantes do grupo PET buscaram auxiliarem os alunos do primeiro período do curso de graduação, apresentando lhes disciplinas e conceitos que atendem ao campo da matemática, bem como consolidar uma estrutura maciça de conhecimento das matérias básicas. As aulas ofertadas seguiram a seguinte ementa:

- Fundamentos de Álgebra: produtos notáveis, fatoração e frações algébricas;

- Números reais: operações e propriedades;

- Resolução de equações e inequações;

- Potências: propriedades e equações exponenciais;

- Logaritmos: definição e propriedades;

- Geometria Analítica: conceitos básicos, estudos da reta e da circunferência;

- Trigonometria: círculo trigonométrico, razões e identidades trigonométricas.

Figura 1- Apresentação do Curso de Nivelamento em Matemática.

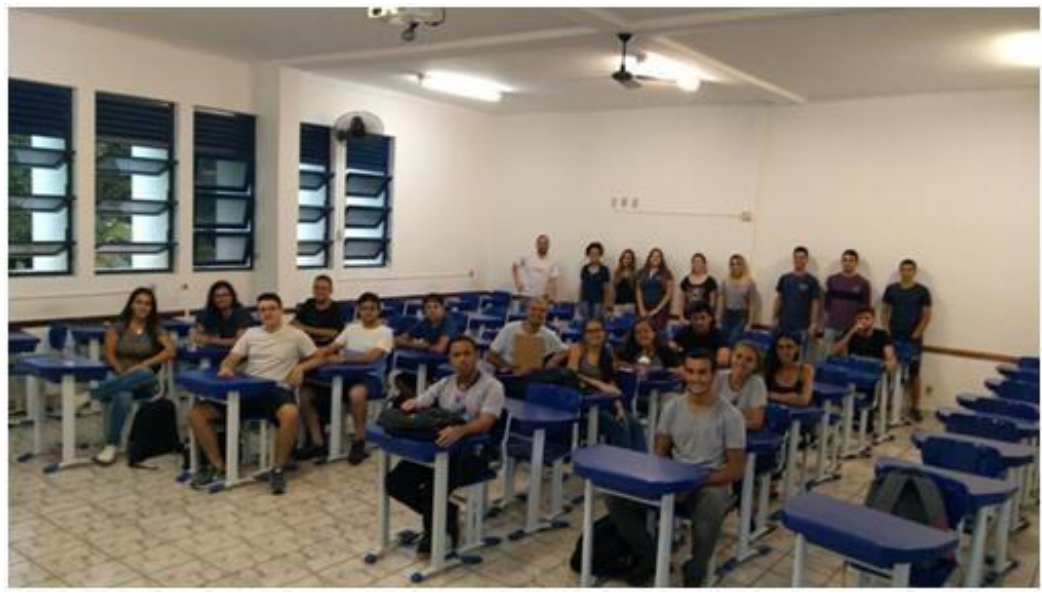

Fonte: Grupo PETEE - Nepomuceno. 
Figura 2- Aula de Nivelamento.

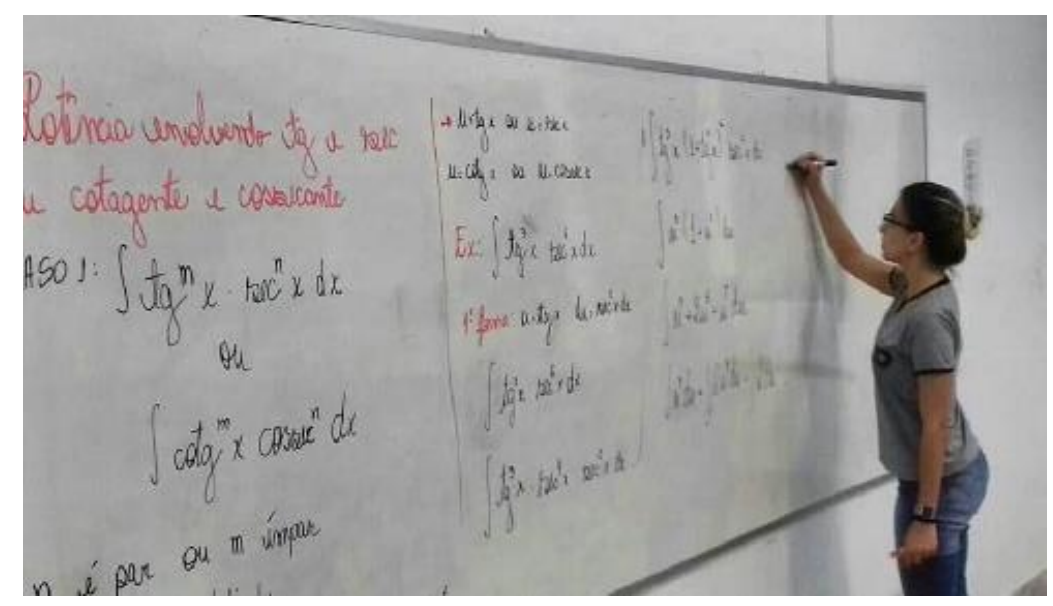

Fonte: Grupo PETEE - Nepomuceno.

A seguir, serão apresentados os resultados obtidos ao final do Curso de Nivelamento em Matemática, ministrados pelos membros do grupo PETEE. Esses resultados exibem a relação da presença dos alunos no curso de Nivelamento com a sua aprovação na disciplina de Cálculo I.

Tabela 1- Dados do Nivelamento no primeiro semestre de 2018.

\begin{tabular}{|c|c|c|}
\hline Total de alunos ingressantes em Cálculo I & Aprovados & $(\%)$ \\
32 & 11 & $34,38 \%$ \\
\hline Participantes do Nivelamento & Aprovados & $(\%)$ \\
15 & 10 & $66,67 \%$ \\
\hline Não participantes do Nivelamento & Aprovados & $(\%)$ \\
17 & 1 & $5,88 \%$ \\
\hline
\end{tabular}

Fonte: CEFET MG - Campus Nepomuceno. 
Figura 3- Gráfico da relação Frequência x Aprovação.

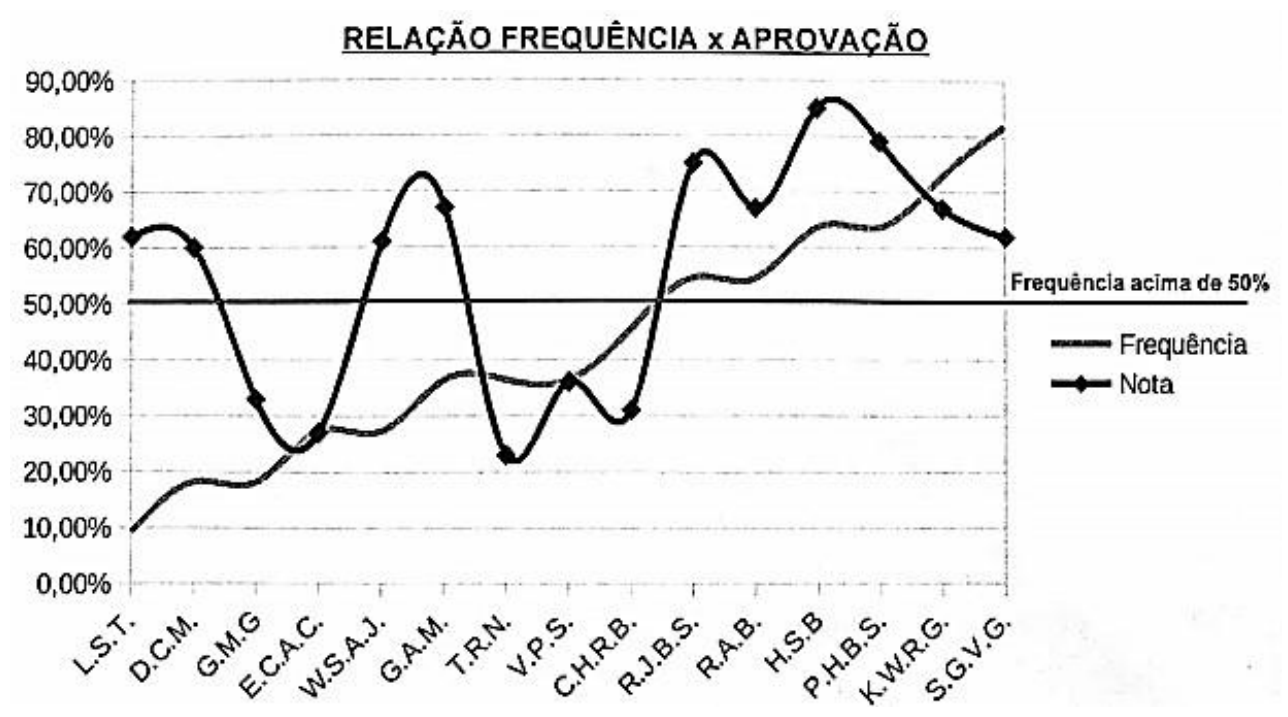

Fonte: CEFET MG - Campus Nepomuceno

A Figura 3 apresenta um gráfico relacionando a porcentagem da frequência de cada aluno matriculado no Curso de Nivelamento, com suas respectivas notas na disciplina de Cálculo I, através do qual, é possível observar que todos os alunos que possuem uma frequência superior a 50\% do Curso de Nivelamento foram aprovados na disciplina de Cálculo I.

No segundo semestre de 2018, os participantes do grupo PETTE, com o intuito de ampliar o acolhimento e o suporte aos alunos ingressantes no primeiro período de Engenharia Elétrica, desenvolveram a atividade denominada Apadrinhamento. $\mathrm{O}$ método fundamentou-se na escolha de dois alunos do período inicial, por parte dos petianos. Assim, cada petiano ficou responsável e comprometido em auxiliar esses alunos, mediante ao compartilhamento de materiais, informações, experiências, entre outras ações.

\section{CONSIDERAÇÕES FINAIS}

A implementação do nivelamento no curso de Engenharia Elétrica no Campus IX foi de grande importância para os discentes ingressantes, fornecendo uma base sólida de conhecimento contemplando o campo da matemática e suas tecnologias, além do esclarecimento de dúvidas referentes as matérias ministradas nos primeiros períodos, tendo como foco Cálculo I e GAAV, visto que estas resultam em maior índice de reprovação. Além do nivelamento, a implantação do apadrinhamento onde cada integrante do grupo PET se responsabilizou pelo acompanhamento de dois ou menos alunos refletiu em uma grande oportunidade de interação entre os alunos do primeiro período e os participantes do Grupo PET (sendo estes de períodos mais avançados), facilitando a disseminação de informações sobre o curso, bem como a transmissão de materiais de estudo referente a matriz curricular do primeiro período e esclarecimento de dúvidas relacionadas a projetos, eventos e seminários realizados no Campus. 


\title{
REFERÊNCIAS
}

ARAÚJO, Evanoel. A.; LOPES, Maria. D.O.; VILHENA, Karyme, S.S. Resultados do Projeto Nivelamento Acadêmico Aplicado ao Ensino de Química Teórica no Campus Universitário de Tucuruí - UFPA. In: XLI - Congresso Brasileiro de Educação em Engenharia, 2013, Gramado. Anais. Gramado, 2013.

BARBOSA, Paola. V.; MEZZOMO, Felipe; LODER, Liane. L. Motivos de Evasão no curso de Engenharia Elétrica: Realidade e perspectivas. In: XXXIX - Congresso Brasileiro de Educação em Engenharia, 2012, Blumenau. Anais. Blumenau, 2012.

BARRETO, L. K. S.; FIGUEIREDO, M. F. A.; MEDEIROS, C. M.; ALVES, M. V. P. C. F. Linguagem, comunicação e inclusão: a importância do curso de nivelamento em língua portuguesa para os cursos superiores de tecnologia da Universidade Potiguar - UNP. Revista Connexio, ano 1, v. 2, p. 99-112, 2011.

FORMIGA, M. Fórum de Debates: Escassez de Engenheiros: mito ou realidade. Sindicato de Engenheiros de Minas Gerais (SENGE-MG), 2011. Disponível em: https://fauufpa.org/2011/03/20/opinioes-\%E2\%80\%93-escassez-de-engenheiros-mitoourealidade/. Acesso em: 15 de maio de 2020.

SILVA FILHO, R.; MONTEJUNAS, P.; HIPÓLITO, O.; LOBO, M. A Evasão no Ensino Superior Brasileiro. Cadernos de Pesquisa. v. 37, n. 132, p. 641-659, São Paulo, set/dez 2007.

\section{LEVELING PROJECT IN MATHEMATICS: A PROPOSAL BY THE PETEE GROUP TO REDUCE EVASION IN ELECTRICAL ENGINEERING AT CEFET-MG CAMPUS NEPOMUCENO}

\begin{abstract}
The tutorial program - PET of the Federal Center of Technological Education of Minas Gerais of Nepomuceno, instituted in October of 2017, is based on the three guidelines: Teaching, Research and Extension. In addition to the other projects focused on Research and Extension, this article will focus on a Teaching project called Leveling in Mathematics. Mathematical Leveling is a discipline that seeks to assist new students with basic topics in the mathematical axis, which is the support for the disciplines of the first period. Initially, this project was carried out by the members of the PET group as a class, and later, in order to promote greater interaction between freshmen and their veterans, the petits changed this method to Sponsorship, where each petite was responsible for asking questions and exchange experiences with one or two freshmen.
\end{abstract}

Keywords: PET. Engineering. Education. Leveling. Mathematics. 